\title{
ATP assay for determining the viability of the two-spotted spider mite (Tetranychus urticae Koch) and the European red mite (Panonychus ulmi (Koch)) (Acari: Tetranychidae) during diapause
}

\author{
Takao EBINA* and Kenji Онто \\ Yokohama Plant Protection Station, Ministry of Agriculture, Forestry and Fisheries of Japan; Yokohama 231-0003, Japan
}

(Received 29 May 2006; Accepted 26 December 2006)

\begin{abstract}
A bioluminescent adenosine triphosphate (ATP) assay for determining viability in adult females of the two-spotted spider mite, Tetranychus urticae, and eggs of the European red mite, Panonychus ulmi, (both diapause and non-diapause state), was investigated. ATP contents in living and dead individual mites (adult females or eggs) were measured. The mites of the lethal treatment group were killed by freezing at $-35^{\circ} \mathrm{C}$. Mean $( \pm \mathrm{SD})$ ATP contents for nondiapause and diapause T. urticae female adults were $34.39 \pm 5.14 \mathrm{pmol}$ and $26.40 \pm 2.67 \mathrm{pmol}$, respectively. Corresponding values for non-diapause and diapause $P$. ulmi eggs were $1.12 \pm 0.19 \mathrm{pmol}$ and $0.87 \pm 0.16 \mathrm{pmol}$, respectively. ATP contents in living mites in diapause were therefore approximately $77 \%$ of those in non-diapause mites. A wide variance in the ATP contents $(0.00-0.94 \mathrm{pmol})$ was found in individual $P$. ulmi diapause eggs at 2 and $4 \mathrm{~h}$ after treatment; therefore, their mean ATP contents did not show a rapid decrease. We speculated that some $P$. ulmi diapause eggs survived for several hours after treatment by cold hardiness, maintaining metabolic activities until death. However, with the exception of $P$. ulmi diapause eggs, ATP contents in both mite species rapidly decreased at $2 \mathrm{~h}$ after treatment. At $24 \mathrm{~h}$ after treatment, ATP contents in both mite species had decreased significantly to $0.4-2.7 \%$ of the pre-treatment values, regardless of whether they were in a non-diapause or diapause state. Thus, based on our findings with $T$. urticae adult females and P. ulmi eggs, the ATP bioluminescence assay could be applicable to the determination of pest viability, regardless of their diapause state.
\end{abstract}

Key words: ATP assay; determining viability; Tetranychus urticae; Panonychus ulmi; plant quarantine

\section{INTRODUCTION}

Adenosine 5'-triphosphate (ATP) is a ribonucleotide produced in metabolic pathways within cells; it stores and provides the energy required to sustain life and various other activities by means of energy-rich phosphate bonds (Lipmann, 1941; Atkinson, 1965). When the cell dies, ATP-degrading enzymes break down ATP until it is completely depleted (Lockshin et al., 1977; Pradet and Raymond, 1983; Forney et al., 1991). Accordingly, since ATP contents differ between living and dead organisms, the reductions in ATP contents after death have been studied in some organisms, for example, yeast (Miller et al., 1978) and fungal spores (Yu et al., 1984), as a means of determining their viability. With respect to insect pests, the eggs and larvae of the Fuller rose beetle, Pantomorus cervinus (Boheman), have been investigated, and they showed clear reductions in ATP contents after lethal treatment (Forney et al., 1991; Ebina et al., 2004). These reports suggest the potential for ATP bioluminescence assays to determine the viability of quarantine pests intercepted at plant quarantine inspections.

Import plant quarantine is conducted at seaports and airports in Japan to prevent the invasion of plant pests or diseases endemic to exporting countries. Viability determination for quarantine pests is required in the shortest possible time so as not to impede the efficient flow of imported plants and plant products. Accordingly, the viability of quarantine pests is primarily determined by visual inspection based on external characteristics, such as

* To whom correspondence should be addressed at: E-mail: atpassay@zau.att.ne.jp DOI: 10.1303/aez.2007.291 
color and shape; however, for some insects, limited information can be gathered from visual inspections alone to determine whether the organisms are alive or dead. Therefore, in addition to visual observations, it is also desirable to develop rapid and reliable methods to determine the viability of quarantine pests.

In such inspections, pests in a diapause state are occasionally found, such as diapausing spider mites. Diapause is a physiological state of arrested development, which enables an organism to more easily survive a period of unfavorable conditions (Dickson, 1949; Jeppson et al., 1975). It is therefore anticipated that diapausing pests will show decreased ATP contents due to reduced metabolic activity. It is further speculated that when ATP contents in the diapause state of pests are very low, or when the decrease in ATP contents following lethal treatment is very small, the use of an ATP bioluminescence assay to determine viability might not be appropriate due to minimal differences in ATP contents between living and dead organisms. Therefore, we investigated the ATP bioluminescence assay method to determine the viability of adult females of the two-spotted spider mite, Tetranychus urticae Koch, and of the eggs of the European red mite, Panonychus ulmi (Koch) in both diapause and non-diapause states. The choice of these organisms was based on their availability for experimentation.

\section{MATERIALS AND METHODS}

In the experiment, $T$. urticae adult females and $P$. ulmi eggs were used. The difference in the diapause stages of these mites (Lees, 1953; Veerman, 1985) accounts for the different stages used in this study.

T. urticae were provided by the Faculty of Horticulture, Chiba University (Chiba Prefecture, Japan), and were maintained at the Research Division, Yokohama Plant Protection Station (YPPS), Ministry of Agriculture, Forestry and Fisheries of Japan (Kanagawa Prefecture, Japan). These mites were reared on bean (Phaseolus vulgaris) leaves placed on paper towels soaked in water in a plastic Petri dish $\left(90 \mathrm{~mm}\right.$ diameter) at $20^{\circ} \mathrm{C}$ and $60-70 \%$ RH under a light-dark photoperiod of 16L:8D. Diapause adult females were selected from those reared from eggs under a short photoperiod
(8L:16D) at $18^{\circ} \mathrm{C}$. Based on the reports by Lees (1953) and Gotoh and Shinkaji (1981), diapause females were identified by a vivid orange pigmentation and the absence of black spots.

P. ulmi were collected from an agricultural test field at the Aomori Prefectural Agriculture and Forestry Research Center in Kuroishi-shi $\left(40^{\circ} 38^{\prime} \mathrm{N} ; 140^{\circ} 37^{\prime} \mathrm{E}\right)$, and were maintained at the Research Division, YPPS. The mites were reared on the leaves of potted apple (Malus domestica) seedlings $\left(40 \mathrm{~cm}\right.$ height, one plant per pot) at $20^{\circ} \mathrm{C}$ and $60-70 \% \mathrm{RH}$ under a photoperiod of $16 \mathrm{~L}: 8 \mathrm{D}$. Non-diapause eggs were collected from those deposited on apple leaves under a photoperiod of 16L:8D. Diapause eggs were obtained from those deposited on apple twigs ( $30 \mathrm{~cm}$ length) infested by adult females, which had been kept under a short photoperiod (8L:16D) at $15^{\circ} \mathrm{C}$. Based on the report by Lees (1953), eggs deposited on twigs and pigmented dark red were identified as being in diapause. After allowing the laying of diapause eggs for 14 days, we cut twigs on which eggs had been deposited into pieces of appropriate length and transferred the pieces to glass tubes $(25 \mathrm{~mm} \times$ $200 \mathrm{~mm}$ ), which were then sealed with cotton wool. Following the reports by Lees (1953) and Tsugawa et al. (1966), the diapause eggs were maintained at $10^{\circ} \mathrm{C}$ (under a short photoperiod) for 30 days after collection, and then at $5^{\circ} \mathrm{C}$ (under complete darkness) for 40-60 days. These low temperature treatments resulted in high hatching ratios of diapause eggs. The hatching ratios of the diapause and nondiapause $P$. ulmi eggs were both approximately 90\%.

ATP contents were measured using a Model AF70 ATP Tester Luminometer (DKK-TOA Corp., Japan). Reagents used for measuring ATP contents were "Luminescent Agent ${ }^{\circledR}$ " (containing firefly luciferase, D-luciferin, tricine, magnesium acetate, magnesium sulfate, dithiothreitol, bovine serum albumin, sucrose and water) and "Extractant Agent $^{\mathbb{R}}$ " (ibid. containing benzalkonium chloride, tricine and water) (DKK-TOA Corp.). Usually, the above mentioned luminometer and reagents are used for microbial control by counting bacteria attached to a surface. The laboratory ware (forceps, glassware, etc.) used for the ATP assay was either autoclaved $\left(120^{\circ} \mathrm{C}, 60 \mathrm{~min}\right)$ or dry heat sterilized $\left(120^{\circ} \mathrm{C}, 3 \mathrm{~h}\right)$, unless it had already been sterilized when purchased and was being used for the first 
time.

ATP content measurements were conducted in accordance with the methods described by Ebina et al. (2004). Luminometer calibration was carried out daily prior to taking measurements using a $100 \mathrm{~nm}$ ATP standard solution. Individual mites (one adult female or one egg) were crushed in $1 \mathrm{ml}$ of a $5 \%(\mathrm{w} / \mathrm{v})$ solution of trichloroacetic acid in $1.5 \mathrm{ml}$ polypropylene tubes. The mixture was left for 10 min with occasional swirling to extract ATP. An aliquot of the mixture $(100 \mu \mathrm{l})$ was diluted with $40 \mathrm{~mm}$ Tris-acetate buffer containing $1 \mathrm{~mm}$ ethylenediaminetetraacetic acid ( $\mathrm{pH}$ 7.8) to a final volume of $1 \mathrm{ml}$. An aliquot of this diluted solution $(100 \mu 1)$ was pipetted into a disposable plastic measurement tube $(12 \mathrm{~mm} \times 55 \mathrm{~mm})$ to which was added $100 \mu 1$ of Luminescent Agent and $100 \mu$ of Extractant Agent giving a total $300 \mu 1$ of solution. Measurements of ATP contents, which required approximately $10 \mathrm{~s}$, were made by placing each disposable tube containing the sample material and reagents in the luminometer. For each test group, blank values (background luminescence) were obtained using a solution of reagents only (without the mite sample). Blank values were subsequently subtracted from mite sample results to give measurements of mite ATP contents corrected for the influence of reagents.

For each test group, we tested 18 T. urticae adult females and 10-18 P. ulmi eggs. For the lethal treatment groups, with the exception of P. ulmi diapause eggs, the mites were killed by freezing at $-35^{\circ} \mathrm{C}$ for $24 \mathrm{~h}$; however, the P. ulmi diapause eggs were killed by freezing at $-35^{\circ} \mathrm{C}$ for 7 days since diapause eggs have been reported to possess cold hardiness (MacPhee, 1961; Tsugawa et al., 1966). It was confirmed that following lethal treatment, all T. urticae adult females were dead, and P. ulmi eggs were incapable of hatching. It was also confirmed that ATP contents did not decrease during the freezing treatment; therefore, the point at which the mite was placed at room temperature after treatment was set as the experimental time of death. ATP contents in individual mites were measured at 2, 4, and $24 \mathrm{~h}$ for $T$. urticae adult females and $P$. ulmi non-diapause eggs, and at 2, 4, 8, and $24 \mathrm{~h}$ for P. ulmi diapause eggs after the treatment (i.e., after the mites were placed at room temperature). Based on the study by Ebina et al. (2004), the measurement at $24 \mathrm{~h}$ after treatment was to determine the
ATP contents of dead mites (i.e., depleted ATP contents), while those at 2 and $4 \mathrm{~h}$ after treatment were to observe the rate of decline in ATP contents.

\section{RESULTS}

The results for $T$. urticae adult females are shown in Fig. 1. ATP contents (mean \pm SD) in nondiapause living females and diapause living females per individual were $34.39 \pm 5.14 \mathrm{pmol}$ and $26.40 \pm 2.67$ pmol, respectively. Thus, ATP contents in diapause females were $76.8 \%$ of those in nondiapause females. For non-diapause females, ATP contents in mites subjected to lethal treatment decreased to $0.45 \pm 0.22 \mathrm{pmol}$ at $2 \mathrm{~h}$ after treatment ( $1.3 \%$ of that in live non-diapause females), and to $0.15 \pm 0.12 \mathrm{pmol}$ at $24 \mathrm{~h}$ after treatment $(0.4 \%$ of that in live non-diapause females) (Fig. 1). Similarly, for diapause females, ATP contents decreased to $0.79 \pm 0.10 \mathrm{pmol}$ at $2 \mathrm{~h}$ after treatment $(3.0 \%$ of that in live diapause females), and to $0.18 \pm 0.06$ pmol at $24 \mathrm{~h}$ after treatment $(0.7 \%$ of that in live diapause females) (Fig. 1). Thus, ATP contents in T. urticae adult females decreased rapidly during the $2 \mathrm{~h}$ after treatment, and remained at a low level until $24 \mathrm{~h}$ after treatment, regardless of whether the female mite was in a non-diapause or diapause state.

The results for $P$. ulmi eggs are shown in Fig. 2. ATP contents (mean \pm SD) in non-diapause and

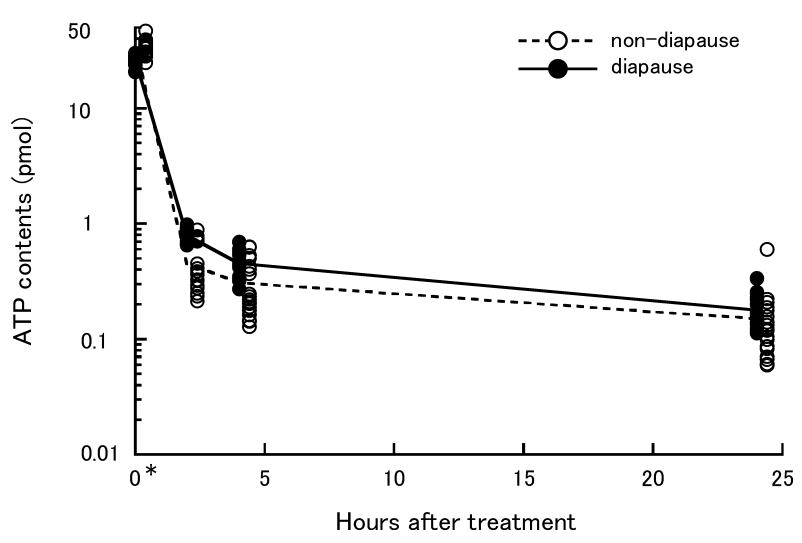

Fig. 1. Reduction in ATP contents in Tetranychus urticae adult females after freezing treatment (lethal treatment) at $-35^{\circ} \mathrm{C}$ for $24 \mathrm{~h}$. Lines represent mean ATP content, and each point represents data for one individual $(n=18)$; dotted line with open circles indicates non-diapause state; solid line with closed circles indicates diapause state. ${ }^{*}$ Data at $0 \mathrm{~h}$ on the $X$ axis indicate ATP content in living mites. 


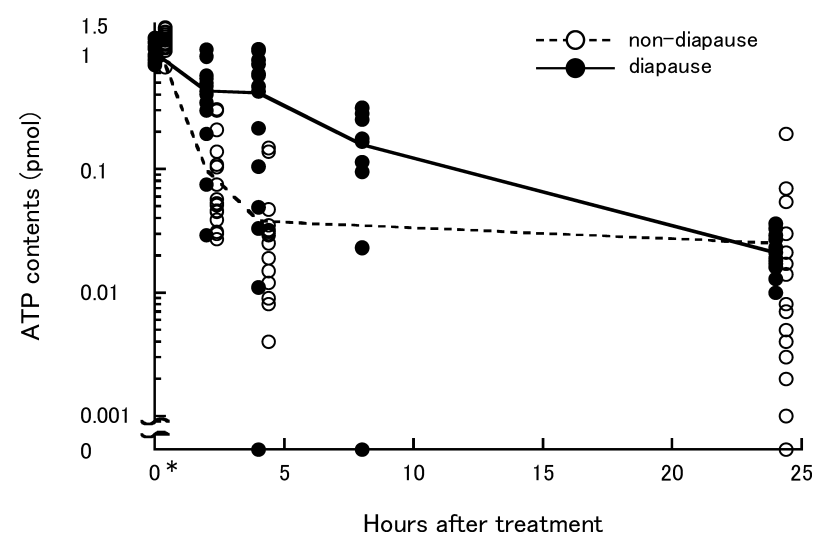

Fig. 2. Reduction in ATP contents in Panonychus ulmi eggs after freezing treatment (lethal treatment) at $-35^{\circ} \mathrm{C}$ for $24 \mathrm{~h}$ (for non-diapause eggs) or 7 days (for diapause eggs). Lines represent mean ATP content, and each point represents data for one individual $(n=10-18)$; dotted line with open circles indicates non-diapause state; solid line with closed circles indicates diapause state. ${ }^{*}$ Data at $0 \mathrm{~h}$ on the $X$-axis indicate ATP content in living mites.

diapause live $P$. ulmi eggs per individual were $1.12 \pm 0.19 \mathrm{pmol}$ and $0.87 \pm 0.16 \mathrm{pmol}$, respectively. Thus, ATP contents in diapause eggs were $77.7 \%$ of those in non-diapause eggs. ATP contents in non-diapause eggs decreased to $0.10 \pm 0.09 \mathrm{pmol}$ at $2 \mathrm{~h}$ after treatment $(8.9 \%$ of that in live non-diapause eggs), and to $0.03 \pm 0.05 \mathrm{pmol}(2.7 \%$ of that in live non-diapause eggs) at $24 \mathrm{~h}$ after treatment (Fig. 2). In contrast, diapause egg ATP contents decreased to $0.43 \pm 0.24 \mathrm{pmol}$ at $2 \mathrm{~h}$ after treatment and to $0.41 \pm 0.34 \mathrm{pmol}$ at $4 \mathrm{~h}$, an overall less prominent decrease (Fig. 2); however, at $24 \mathrm{~h}$ after treatment, diapause egg ATP contents had declined to $0.02 \pm 0.01 \mathrm{pmol}(2.3 \%$ of that in live diapause eggs), which was almost as the same as that recorded in non-diapause eggs (Fig. 2).

In addition to these results, it has been proved that ATP contents (mean $\pm \mathrm{SD} ; n=5$ ) in individual living T. urticae eggs were $1.36 \pm 0.09 \mathrm{pmol}$ (Ebina, unpublished); therefore, it was considered that the different ATP content between T. urticae females $(34.39 \pm 5.14 \mathrm{pmol})$ and P. ulmi eggs $(1.12 \pm 0.19$ pmol) was due to their different body size.

\section{DISCUSSION}

It was observed that ATP contents in T. urticae diapause adult females and $P$. ulmi diapause eggs were approximately $77 \%$ of those in non-diapause mites (T. urticae diapause adult females, 76.8\%; $P$. ulmi diapause eggs, 77.7\%). Although the individuals studied represent two different species and have different diapause stages (adult or egg), their ATP production and consumption in the diapause state can be regarded as similar. The physiological features associated with the diapause state are generally known to include markedly reduced metabolic activity (Danilevskii, 1961); this, in turn, is likely to account for a reduction in ATP demand and suppression of ATP production, thereby resulting in a decrease in ATP contents. ATP consumption of diapause mites was also considered to be lower than that of non-diapause mites. While McEnroe (1961) reported that oxygen consumption via external respiration in diapause adult females of T. urticae was $19.3 \%$ of that in non-diapause females, the reduction in ATP content during diapause was not as pronounced as that in oxygen consumption. Results from the present study showed that ATP contents in mites in diapause, which is a state of suppressed metabolic rate and other activities, were relatively similar to those in the non-diapause state.

ATP contents in $T$. urticae adult females and $P$. ulmi eggs decreased significantly in the $24 \mathrm{~h}$ following lethal treatment, regardless of whether they were in a non-diapause or diapause state (Figs. 1 and 2). With the exception of P. ulmi diapause eggs, ATP contents in mites of both species decreased rapidly at $2 \mathrm{~h}$ after treatment. These findings are in accordance with studies showing that ATP contents of $P$. cervinus larvae and eggs are reduced at $2 \mathrm{~h}$ after lethal treatment to $1 \%$ or less of the values measured when alive (Forney et al., 1991; Ebina et al., 2004). As noted above, rapid decreases in ATP contents are considered attributable to the fact that while ATPs are actively produced by metabolic processes in living cells, they are readily broken down by ATP-degrading enzymes after cell death.

Mean ATP contents in P. ulmi diapause eggs did not show a rapid decrease (Fig. 2); however, some P. ulmi diapause eggs were observed to have significantly lowered ATP contents at 2 and $4 \mathrm{~h}$ after treatment (Fig. 2). This indicates the possibility that $P$. ulmi diapause eggs could display a rapid postmortem decrease in ATP contents. If ATP contents decrease uniformly and slowly after treatment, this should occur in all individuals. Figure 2 
shows a wide variance in ATP contents (0.00-0.94 pmol) in P. ulmi diapause eggs at 2 and $4 \mathrm{~h}$ after treatment. It is speculated that this variance is presumably attributable to the cold hardiness of $P$. ulmi diapause eggs. Organisms in diapause are known to have higher survival rates under low temperature conditions than those in non-diapause states, as shown in a previous cold hardiness study on diapause pupae of the flesh fly, Sarcophaga crassipalpis (Lee and Denlinger, 1985). Similarly, P. ulmi diapause eggs are reported to show cold hardiness and enhanced freezing tolerance when maintained at or below $-30^{\circ} \mathrm{C}$ (MacPhee, 1961); therefore, non-diapause and diapause eggs are believed to display differential sensitivity to lethal treatment (freezing at $-35^{\circ} \mathrm{C}$ ) implemented in this study. Diapause eggs eventually died after lethal treatment, but some of the eggs survived for several hours, maintaining metabolic activities until death. In other words, it was assumed that although ATP contents in P. ulmi diapause eggs rapidly decreased after they died, there were individual differences in the length of time prior to death. At $8 \mathrm{~h}$ after treatment, no individuals (diapause eggs) kept the same level of ATP contents as in live eggs, and as a result, their mean ATP content was apparently lower than in live eggs (Fig. 2); thus, it is considered that the number of live eggs decreased over time following lethal treatment. At $24 \mathrm{~h}$ after treatment, ATP contents in P. ulmi diapause eggs exhibited a decrease similar to that observed in non-diapause eggs (Fig. 2). These findings appear to indicate the practical applicability of the present technique to $P$. ulmi diapause as well as non-diapause eggs.

With a view to applying ATP bioluminescence assays to viability determinations of quarantine pests, it is essential to confirm clearly observable differences in ATP contents before and after the death of organisms. The results of the present study indicate that the above requirements are satisfied with respect to diapause mites. Based on our findings with T. urticae adult females and P. ulmi eggs, the ATP bioluminescence assay could be applicable to the determination of pest viability, regardless of their diapause state.

\section{ACKNOWLEDGEMENTS}

We thank Y. Haketa (DKK-TOA Corporation) for his advice concerning the measurement of ATP contents, and K. Kimura (Aomori Prefectural Agriculture and Forestry Research Cen- ter) for providing the European red mites used in this study. We also thank S. Sugimoto (Food Safety and Consumer Affairs Bureau, MAFF), and H. Someya, M. Tanaka, Y. Tatematsu, T. Imamura and the other staff of the Yokohama Plant Protection Station, MAFF of Japan, for their useful suggestions.

\section{REFERENCES}

Atkinson, D. E. (1965) Biological feedback control at the molecular level. Science 150: 851-857.

Danilevskii, A. S. (1961) Photoperiodism and Seasonal Development of Insects (English edition, J. Jonston and N. Waloff eds., Oliver and Boys Ltd., Edinburg, 1965). Leningrad University Press, Leningrad. 283 pp.

Dickson, R. C. (1949) Factors governing the induction of diapause in the oriental fruit moth. Ann. Entomol. Soc. Am. 42: 511-537.

Ebina, T., M. Kaneda and K. Ohmura (2004) ATP assay for determining egg viability of the Fuller rose beetle, Pantomorus cervinus (Boheman) (Coleoptera: Curculionidae). Res. Bull. Plant Prot. Japan 40: 69-73 (in Japanese with English summary).

Forney, C. F., L. H. Aung, D. G. Brandl, E. L. Soderstrom and J. I. Moss (1991) Reduction of adenosine triphosphate in eggs of Fuller rose beetle (Coleoptera: Curculionidae) induced by lethal temperature and methyl bromide. $J$. Econ. Entomol. 84: 198-201.

Gotoh, T. and N. Shinkaji (1981) Critical photoperiod and geographical variation of diapause induction in the twospotted spider mite, Tetranychus urticae Koch (Acarina: Tetranychidae), in Japan. Jpn. J. Appl. Entomol. Zool. 25: 113-118 (in Japanese with English summary).

Jeppson, L. R., H. H. Keifer and E. W. Baker (1975) Mites Injurious to Economic Plants. University of California Press, Berkely. 591 pp.

Lee, R. E., Jr. and D. L. Denlinger (1985) Cold tolerance in diapausing and non-diapausing stages of the flesh fly, Sarcophaga crassipalpis. Physiol. Entomol. 10: 309315.

Lees, A. D. (1953) Environmental factors controlling the evocation and termination of diapause in the fruit tree red spider mite Metatetranychus ulmi Koch (Acarina: Tetranychidae). Ann. Appl. Biol. 40: 449-486.

Lipmann, F. (1941) Metabolic generation and utilization of phosphate bond energy. Adv. Enzymol. 1: 99-162.

Lockshin, R. A., R. Schlichtig and J. Beaulaton (1977) Loss of enzymes in dying cells. J. Insect Physiol. 23: 11171120.

MacPhee, A. W. (1961) Mortality of winter eggs of the European red mite Panonychus ulmi (Koch), at low temperatures, and its ecological significance. Can. J. Zool. 39: 229-243

McEnroe, W. D. (1961) The control of water loss by the twospotted spider mite (Tetranychus telarius). Ann. Entomol. Soc. Am. 54: 883-887.

Miller, L. F., M. S. Mabee, H. S. Grees and N. O. Jangaard (1978) An ATP bioluminescence method for the quantification of viable yeast for fermenter pitching. J. Am. Soc. Brew. Chem. 36: 59-62. 
Pradet, A. and P. Raymond (1983) Adenine nucleotide ratios and adenylate energy charge in energy metabolism. Annu. Rev. Plant Physiol. 34: 199-224.

Tsugawa, C., M. Yamada, S. Shirasaki and N. Oyama (1966) Forecasting the outbreak of destructive insects in apple orchards. VII. Termination of diapause in hibernating eggs of Panonychus ulmi (Koch) in relation to temperature. Jpn. J. Appl. Entomol. Zool. 10: 174-180 (in
Japanese with English summary).

Veerman, A. (1985) Diapause. In Spider Mites: Their Biology, Natural Enemies and Control. Vol. 1A (W. Helle and M. W. Sabelis eds.). Elsevier, Amsterdam, pp. 279-316.

Yu, S. Q., E. J. Trione and T. M. Ching (1984) Biochemical determination of the viability of fungal spores and hyphae. Mycologia 76: 608-613. 